Article

\title{
The Role of the Laser Photobiomodulation (PBM) in the Management of Patients at Risk or Affected by MRONJ
}

\author{
Alessandro Del Vecchio, Gianluca Tenore $\mathbb{D}$, Daniele Pergolini * ${ }^{\mathbb{C}}$, Federica Rocchetti, Gaspare Palaia \\ and Umberto Romeo
}

check for updates

Citation: Del Vecchio, A.; Tenore, G.; Pergolini, D.; Rocchetti, F.; Palaia, G.; Romeo, U. The Role of the Laser Photobiomodulation (PBM) in the Management of Patients at Risk or Affected by MRONJ. Oral 2022, 2 , 7-15. https://doi.org/10.3390/ oral2010002

Received: 12 December 2021

Accepted: 13 January 2022

Published: 17 January 2022

Publisher's Note: MDPI stays neutral with regard to jurisdictional claims in published maps and institutional affiliations.

Copyright: (C) 2022 by the authors. Licensee MDPI, Basel, Switzerland. This article is an open access article distributed under the terms and conditions of the Creative Commons Attribution (CC BY) license (https:// creativecommons.org/licenses/by/ $4.0 /)$.
Department Oral Science and Maxillo-Facial Surgery, Sapienza University of Rome, 00161 Rome, Italy; alessandro.delvecchio@uniroma1.it (A.D.V.); gianluca.tenore@uniroma1.it (G.T.);

federica.rocchetti@uniroma1.it (F.R.); gaspare.palaia@uniroma1.it (G.P.); umberto.romeo@uniroma1.it (U.R.)

* Correspondence: daniele.pergolini@uniroma1.it; Tel.: +39-3396803461

\begin{abstract}
Medication-Related Osteo-Necrosis of the Jaws (MRONJ) is a severe painful complication of the long-lasting administration of bisphosphonates and anti-resorptive and anti-angiogenetic drugs in neoplastic and dysmetabolic patients, secondary to minor surgical oral interventions or chronic epithelial decubitus ulcers. Its pathogenesis is still largely unknown even if the activity change of the osteoclasts plays a relevant role in bone remodeling. The management of these patients aims to prevent the onset of the pathology or to reduce the pain and remove the necrotic bone, promoting the healing of the pathological area. Photobiomodulation therapy (PBMT), the therapeutic application of low-energy laser or LED lights, was recently introduced in the management of this condition. Thanks to its therapeutic and biomodulating action on the irradiated tissues, PBM can be used alone or in combination with antibiotic and antibacterial therapies as a preventive, antalgic or palliative tool, and in support of surgery in a combined multi-protocol that leads to a positive and better resolution and healing of the pathologic process, with great improvement of the Quality of Life (QoL) of the patients. In this narrative review, a wide analysis of the various applications of PBM in MRONJ patients' management is analyzed, emphasizing its role as supportive care for this condition.
\end{abstract}

Keywords: photobiomodulation; PBM; osteonecrosis of the jaws; MRONJ; prevention; supporting care; L-PRF; hemoderivatives

\section{Introduction}

Since its first observation in 2003, Bisphosphonates-Related Osteonecrosis of the Jaws (BRONJ) has become an increasing problem for both practitioners and patients due to the severe progressive destruction of the bone of the mandible and/or maxilla after oral surgery treatments, or even after simple slight traumas to the oral mucosa, such as the ones induced by unfitting removable dentures.

Initially identified as a negative side effect of long-lasting bisphosphonate administration (e.g.: alendronate, zoledronate) [1,2], in recent years, it has also been observed as an adverse side effect of the administration of other medications such as: antiresorptive (denosumab) [3] and antiangiogenics such as sunitinib, bevacizumab, etc. [4]. This led to the identification of this condition with its present denomination of Medication-Related ONJ (MRONJ) defined by the SIPMO Consensus Conference in 2018 as "adverse drug reaction described as the progressive destruction and death of bone that affects the mandible and maxilla of patients exposed to the treatment with medications known to increase the risk of disease, in the absence of a previous radiation treatment" [2].

Although many studies on the pathogenesis of MRONJ have been carried out, the clear cause of the disease is not yet completely understood, probably being multifactorial. Altered bone remodeling, the over-suppression of bone resorption, angiogenesis inhibition, immunodeficiency, and vitamin D deficiency, have been suggested as explanations for 
MRONJ. In addition, many co-factors, such as comorbidities (e.g., diabetes), smoking, dental interventions, and concurrent medications (e.g., corticosteroids), have been reported to play a role in its pathogenesis [5]. Bone progressive exposure and pain are the most severe complications of MRONJ, and their onset was demonstrated to greatly reduce the Quality of Life (QoL) of patients [2,6,7].

There is no general consensus on the management of MRONJ in the literature, and its treatment is very difficult and debated [8-11]. The main target of all therapeutic protocols is to minimize the occurrence or the progression of bone necrosis, to eliminate pain, to control infection and suppuration, and to provide some relief to patients [6,8-11].

As in many other pathologies, prevention is always the main focus in patients following at-risk MRONJ therapeutic protocols; conservative measures, such as good oral hygiene, $0.12 \%$ chlorhexidine mouthwashes, and the treatment of any early dental or periodontal lesions are fundamental. In fact, any surgical intervention should be avoided, though the prevention of this may lead to areas of exposed necrotic bone [6]. In the past, the onset of the lesions was thought to be related to minor oral surgery in at-risk patients being administered drugs for long periods; on the contrary, recently, periodontal and periimplant infections have been considered as crucial risk factors, being the sites that often need surgical dental or implant removal, and so leading to the onset of MRONJ lesions [2].

In the case of patients with established MRONJ at early or advanced stages, surgical interventions, (e.g., surgical debridements or resections), in combination with antibiotic and antibacterial therapies, are considered more appropriate. In many cases, different supporting therapies to surgical intervention were proposed in the literature with somewhat beneficial results. Biological agents, such as autologous platelet concentrates, recombinant growth and differentiation factors, parathyroid hormone (PTH, teriparatide), hyperbaric oxygen therapy (HBO), ozone therapy and recently photobiomodulation (PBM), have been used to enhance bone and soft tissue healing in MRONJ [8,12].

PBM is the application of low amounts of red or near-infrared (NIR) light to heal, restore, and stimulate physiological cellular processes, and to repair tissue damages caused by several injuries or diseases $[13,14]$. The emitted photons reach their main chromophore, the molecule that can effectively absorb their energy, which is the Cytochrome c-oxidase $(\mathrm{COX})$ in the inner mitochondrial membrane, without heating the targeted tissues; COX is a crucial element of the Electron Transport Chain (ETC) and its activation leads to an enhancement of the production of energy by the cells, stored in the high-energy bond of adenosine triphosphate (ATP). In the meantime, the light action induces the release of discrete amounts of reactive oxygen species (ROS), and the release of nitric oxide (NO) [15].

These molecules induce, in a dose-dependent manner, via the mechanism of the "second messenger" (e.g., NF-kB), the activation of several genes in the cellular nucleus, promoting the production of growth factors and enhancing the cells' viability and motility. Moreover, the NO, released outside the cells, acts as a powerful vasodilator, improving the local microcirculation and allowing a better arrangement of the local repairing processes $[16,17]$.

Since the highest peaks of light absorption of Cytochrome c-oxidase range between $620 \mathrm{~nm}$ and $820 \mathrm{~nm}$, it is fundamental that the therapeutic laser wavelength is in the socalled "therapeutic window", between approximately $600 \mathrm{~nm}$ and $1200 \mathrm{~nm}$, to promote the best tissue response.

Like other therapeutic agents, as common drugs, PBM follows the rules of the "biphasic dose-response", or Arndt-Schulz curve [18], a principle that states that there are specific "optimal" parameters (energy density or power density), identified as the proper light dose, which provide a therapeutic and positive action on the targeted tissues; below these dosages, the irradiation does not produce any effect, while if the dosage is significantly exceeded, the irradiation may lead to inhibitory and even toxic effects. This phenomenon is also called "hormesis" and has been demonstrated by many authors in the literature $[19,20]$.

The correct identification of the proper dose is not an easy process in the PBM, due to the numerous parameters by which lasers emit their energy (e.g., power, energy, frequency, 
etc.) and this leads to a lack of standardized protocols in the various clinical applications. However, even without a definitive consensus, there is a large amount of clinical evidence that supports the beneficial effects of the PBM in many pathological conditions, as wound repair [21], pain relief [22], and neuronal regeneration [23].

In the management of the patients affected, or simply at risk of MRONJ, the PBM can be applied in four different ways: preventive, antalgic, "palliative" and as support of conventional surgical treatments with or without the application of hemoderivatives [24].

The aim of this paper is to provide a narrative review of the different applications of the PBM in MRONJ patients, emphasizing their role in the management of the clinical manifestations of the pathology and in the improvement of the QoL of the patients.

\section{Preventive Application}

Many authors have studied the beneficial effects of the PBM on the trophism of the irradiated tissues, which better supports the organism and allows it to react to pathologic stimuli. All these evaluations led to a wide range of applications in many potentially pathologic conditions, as in the management of the chemo- or radio-induced oral mucositis [25], and similarly the MRONJ [26].

This effect is considered due to the increased cell metabolism and to the reduction in inflammatory processes in the irradiated areas, beyond a stimulatory effect of the local immune response that, taken together, allow the tissues to react better to negative and potentially harmful local stimuli.

This extensive research led to the development of two important associations: the Multinational Association of Supporting Care in Cancer (MASCC) and the International Society of Oral Oncology (ISOO). These were introduced in their clinical recommendations, the application of preventive protocols of PBM in the prevention of the oral mucositis induced by high-dosage chemo-therapy in the patients receiving Hematologic Stem Cell Transplantation (HSCT) even in the lack of a general consensus about the protocols of administration [27].

Analogously, PBM has been evaluated and performed with beneficial effects in patients receiving therapies at risk for MRONJ who, for different reasons, could not suspend their therapies and contemporarily needed minor oral surgical interventions.

Vescovi et al. [26] in a case series of 589 surgical sites reported only five cases of ONJ through the application of the preventive PBM in these patients. In the study, the PBM was administered immediately after the extraction and weekly for the following six week, over the surgical site, in combination with antibiotic and anti-bacterial therapy. A preventive administration of PBM in patients at-risk for MRONJ has been described by Nica et al. too. In their 84-patient case series the authors applied the laser therapy immediately after the teeth extraction and, daily for the successive three weeks until the complete bone and mucosal healing, reporting no osteonecrotic lesions onset in all the studied cases [6].

Similar approach we apply at the Department of Dental Sciences of Sapienza University in Rome. In a preliminary case series of 57 oral sites of patients receiving different therapies at risk for MRONJ, who needed minor oral surgical interventions, the preventive application of PBM by a double-diode superpulsed GaAlAs laser $(650 \mathrm{~nm}$ and $910 \mathrm{~nm}$, Lumix 2 Fisioline, Verduno, (CN) Italy) with the administration of $243 \mathrm{~J}$ in scanning mode, $30 \mathrm{kHz}$, and $100 \%$ duty cycle, (Figure 1), in association with antibiotic and antibacterial therapy, led to a positive result with no necrotic lesions at three months of follow up even without interruption of the at risk drug administration. 


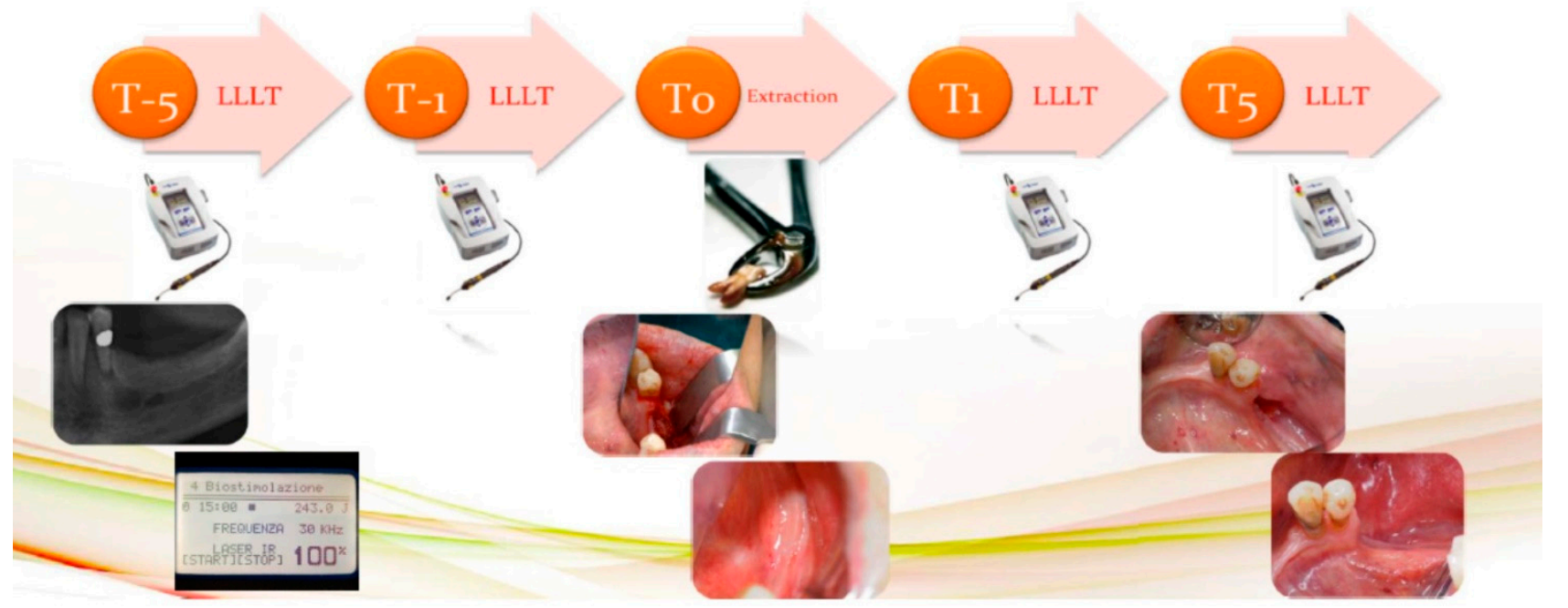

Figure 1. Protocol scheme of the preventive PBM applications in patients needing minor oral surgery interventions that cannot interrupt the drug assumption.

All of these observations suggest that even in the lack of a consensus regarding the protocol of administration, the PBM may play an effective preventive role in the irradiated tissue, maybe due to the local immune stimulation that may lead to a better reaction against the damaging stimuli induced by the extractive surgery in the maxillary bone altered by the pharmacological therapy.

\section{Antalgic Application}

There is a similar wide consensus in the literature about the antalgic action of the $\mathrm{PBM}$, even if the real mechanism by which the treatment induces pain relief remains largely debated. Many authors suggest the main role played by the increased cellular activity that lead to a better recovery from fatigue by stressed cells [28]; other studies emphasize the release of peripheral endogenous opioids [29], while other authors suggest a reversible neuronal blockade of $\mathrm{A} \delta$ and $\mathrm{C}$ nociceptors that would induce a neurotransmission failure [30]. Other studies support the hypothesis that the reduction in pain would be a secondary effect of the anti-inflammatory action induced by the light irradiation [31]. As in many cases, it can be hypothesized that all these effects may have a synergistic action and, to different degrees, they induce the pain-relieving effect so widely demonstrated in many studies in the literature [32]. So far, the PBM has been largely adopted in the management of the pain associated with the MRONJ and several studies emphasized this positive effect that improves the QoL of these patients [7,12,26]. Tenore et al. [33], in a clinical trial performed in our Department at Sapienza University of Rome, observed a reduction of at least 4 points of the Numeric Rating Scale (NRS) pain score, in $88 \%$ of the 25 patients included in their study. The patients received, beyond the conventional antibiotic and antiseptic therapy, a PBM antalgic support, by a double-diode laser (Lumix ${ }^{\circledR}$; FISIOLINE, Verduno, Italy); $650 \mathrm{~nm}$ at $100 \mathrm{~mW}$ in CW, and $904-910 \mathrm{~nm}$ superpulsed at $50 \mathrm{kHz}$, peak power of $45 \mathrm{~W}$ and average power of $500 \mathrm{~mW}$; spot beam diameter of $0.8 \mathrm{~cm}$ and $34.8 \mathrm{~J}$ per session each third day for five sessions. During these antalgic applications, it was also observed a relatively fast detachment of the sequestered bone fragment, maybe due to the positive action of the PBM on the keratinocytes, which promotes a rapid closure of the superficial epithelial wound as demonstrated experimentally by Jae Yeol Lee et al. [34].

\section{4. "Palliative" Support}

This latter observation induced also in a further and alternative adoption of the PBM as "palliative" support for some patients. In fact, in consideration of the fact that most of these patients are affected by severe and debilitating pathologies, mostly of oncologic nature, the MRONJs represent a further and severe complication of their treatment. For these reasons, 
often they do not tolerate, neither accept, the proposed demolitive combined intervention of surgical removal of the bone sequestrum followed by a complex reconstructive phase. In all the cases in which surgery is not feasible, we find it helpful even, if not resolutive, to apply the PBM irradiation to reduce the pain induced by the necrosis and to promote the relative fast detachment of the necrotic fragments, with a reduction in the general discomfort induced by the oral condition. The protocol adopted is structured by the irradiation by a double-diode GaAlAs Red $650 \mathrm{~nm}$ and superpulsed NiR $910 \mathrm{~nm}$ laser (Lumix 2, Fisioline, Verduno (CN), Italy) with an irradiation of $243 \mathrm{~J}$ in scanning mode for $15 \mathrm{~min}$ each third day for a total of 8 to 10 applications at least, till the bone detachment (Figures 2-4). This protocol represents a good compromise in these cases, improving the symptomatology and relieving the disturbance produced by the bone necrosis.

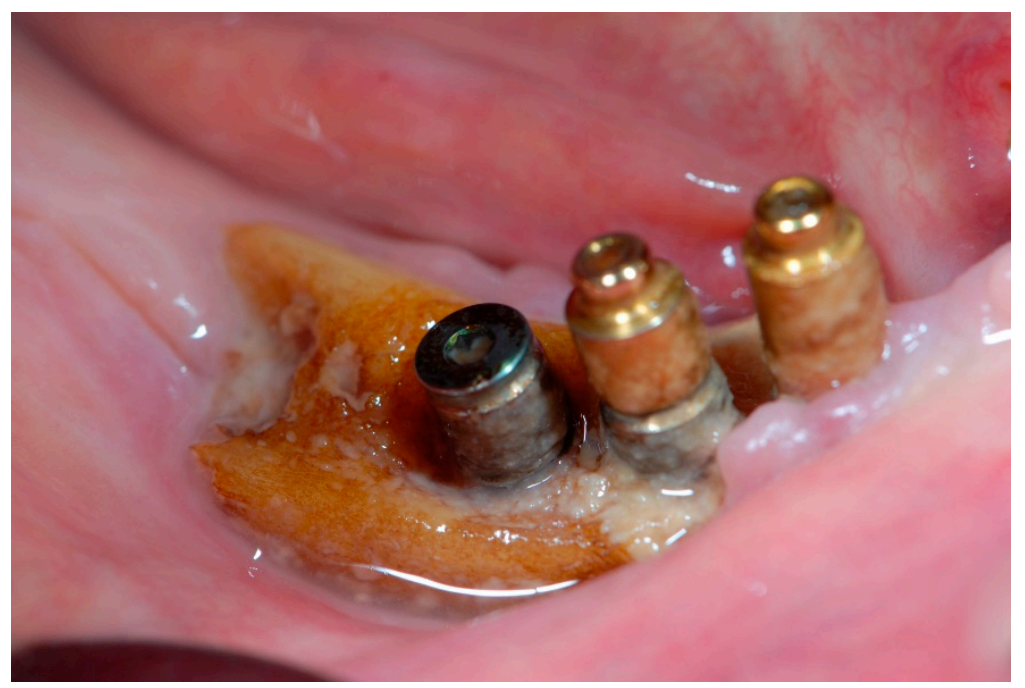

Figure 2. Clinical aspect of a patient affected by grade 3 MRONJ who received "palliative" PBM application over a large bone exposition around the implants.

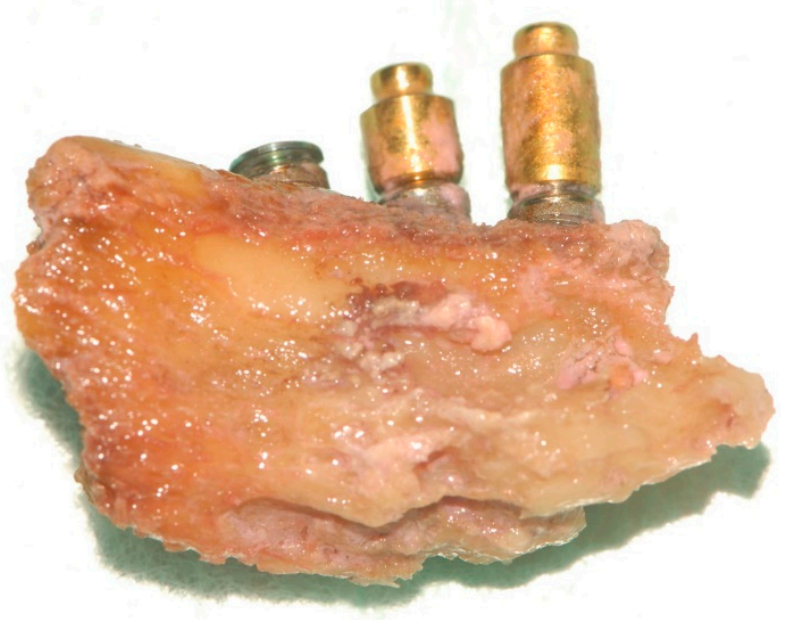

Figure 3. Macroscopic aspect of the detached necrotic bone fragment that includes the implants. 


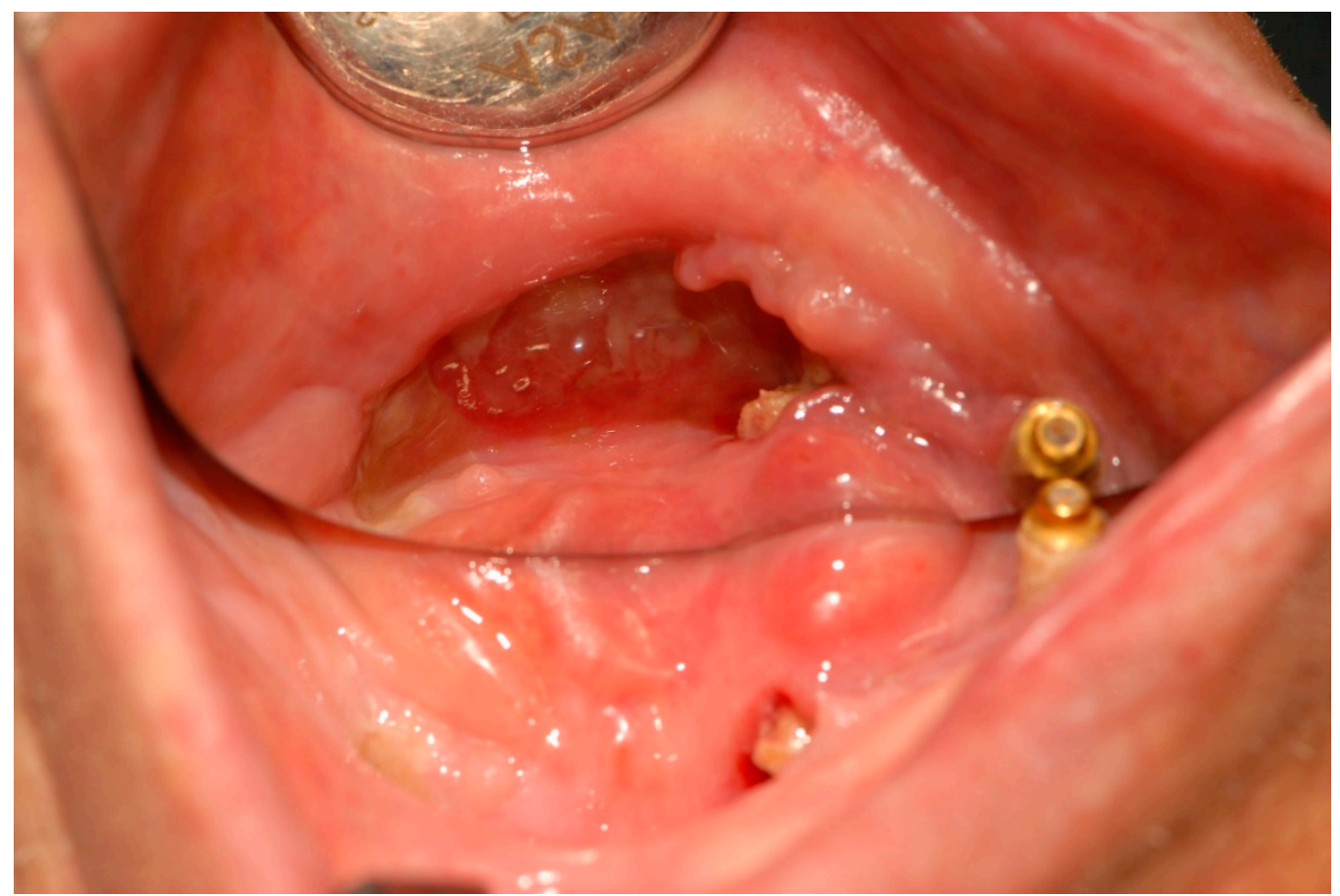

Figure 4. Clinical aspect of the patient after the detachment of the necrotic bone fragment.

\section{Supportive Therapy}

Autologous hemoderivatives, as PRP, L-PRF, etc., have been introduced in oral surgery in the last twenty years, confirming their positive efficiency in the bone remodeling and healing processes. In many studies, they have been introduced in the post-surgical phase of MRONJ patients [6]. The association of surgical therapy, pharmacological therapy, PRP and PBM induced a complete response and a positive outcome for most of a case series analyzed by Martins et al. [35]. The authors emphasize that the antimicrobial control and the positive neovascularization and new bone remodeling induced by the association of the PRP and PBM permitted a better arrangement of the surgical site enhancing results obtained with the sole mechanical resection. More recently, Tenore et al. in a retrospective study, observed the best outcome of a combined protocol including surgery, antibiotics, L-PRF and PBM with total healing and no recurrences at three and six months, in comparison with other therapy plans performed with antibiotic and surgery, or antibiotic and PBM, respectively [24].

In our clinical practice, the combined therapy is performed by a protocol that previews a pre-surgical pharmacological phase of antibiotic and antibacterial administration beginning one week before the surgical treatment; then, the bone fragment is removed surgically with the application of the L-PRF membranes as biological barrier against bacterial recolonization and source of growth factors for vascular and bone regeneration. The PBM is performed for 7 days after the surgery by superpulsed double-diode GaAlAs laser (Lumix Dental, Verduno, (CN), Italy; at $650 \mathrm{~nm} 0.1 \mathrm{~W}$ CW, and $810 \mathrm{~nm} 0.5 \mathrm{~W}$ SPS; $30 \mathrm{kHz}$, $577.4 \mathrm{~J}$ in scanning mode, for $15 \mathrm{~min}$, in association with antibiotic therapy and antiseptic mouthwashes as in the pre-surgical phase (Figure 5). 


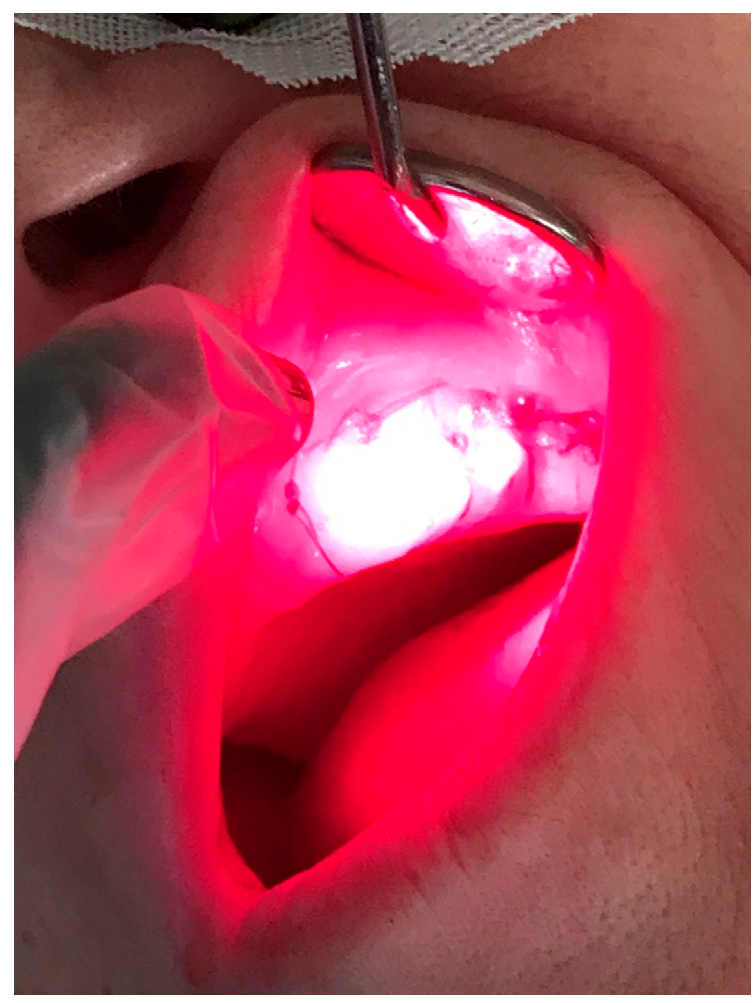

Figure 5. PBM therapeutic support. Laser application after the surgical removal of the necrotic bone fragment and the application of the L-PRF membrane.

A preliminary report of this protocol showed the complete resolution in 11 of 11 cases analyzed with 3 and 6 moths follow up, confirming the positive outcomes widely reported in the literature $[6,24,26,35]$.

\section{Conclusions}

The present review demonstrates that the PBM may play a very important role in the management of patients at risk and/or affected by various degrees of MRONJ. In the first case, biomodulating laser applications reduced the risk of the onset of necrotic lesions in patients needing minor oral surgery interventions but for whom it is not possible to interrupt the assumption of MRONJ at risk protocols. In all the remnant cases, the laser applications are of great support thanks to the reduction in pain induced by laser action and its antibacterial and stimulatory effects on both the bone and the hemoderivatives applied to stimulate the healing of the surgical site.

Author Contributions: Conceptualization, supervision U.R.; writing—original draft preparation, A.D.V. and D.P.; investigation, F.R., G.P. and G.T. All authors have read and agreed to the published version of the manuscript.

Funding: This research received no external funding.

Institutional Review Board Statement: This study does not require the approval of the ethics committee, as it is a narrative review.

Informed Consent Statement: Not applicable.

Conflicts of Interest: The authors declare no conflict of interest. 


\section{References}

1. Bagan, J.V.; Hens-Aumente, E.; Leopoldo-Rodado, M.; Poveda-Roda, R.; Bagan, L. Bisphosphonate-related osteonecrosis of the jaws: Study of the staging system in a series of clinical cases. Oral Oncol. 2012, 48, 753-757. [CrossRef]

2. Campisi, G.; Mauceri, R.; Bertoldo, F.; Bettini, G.; Biasotto, M.; Colella, G.; Consolo, U.; Di Fede, O.; Favia, G.; Fusco, V.; et al. Medication-Related Osteonecrosis of Jaws (MRONJ) Prevention and Diagnosis: Italian Consensus Update 2020. Int. J. Environ. Res. Public Health 2020, 17, 5998. [CrossRef]

3. Egloff-Juras, C.; Gallois, A.; Salleron, J.; Massard, V.; Dolivet, G.; Guillet, J.; Phulpin, B.; Aurélie, G.; Julia, S.; Vincent, M.; et al. Denosumab-related osteonecrosis of the jaw: A retrospective study. J. Oral Pathol. Med. 2017, 47, 66-70. [CrossRef]

4. Eguia, A.; Bagán-Debón, L.; Cardona, F. Review and update on drugs related to the development of osteonecrosis of the jaw. Med. Oral Patol. Oral Cirugia Bucal 2020, 25, e71-e83. [CrossRef]

5. Tartaroti, N.C.; Marques, M.M.; Naclério-Homem, M.D.G.; Migliorati, C.A.; Deboni, M.C.Z. Antimicrobial photodynamic and photobiomodulation adjuvant therapies for prevention and treatment of medication-related osteonecrosis of the jaws: Case series and long-term follow-up. Photodiagn. Photodyn. Ther. 2020, 29, 101651. [CrossRef]

6. Nica, D.; Riviș, M.; Roi, C.; Todea, C.; Duma, V.-F.; Sinescu, C. Complementarity of Photo-Biomodulation, Surgical Treatment, and Antibiotherapy for Medication-Related Osteonecrosis of the Jaws (MRONJ). Medicina 2021, 57, 145. [CrossRef]

7. Tenore, G.; Mohsen, A.; Rossi, A.F.; Palaia, G.; Rocchetti, F.; Cassoni, A.; Valentini, V.; Ottolenghi, L.; Polimeni, A.; Romeo, U. Does Medication-Related Osteonecrosis of the Jaw Influence the Quality of Life of Cancer Patients? Biomedicina 2020, 8, 95. [CrossRef] [PubMed]

8. Goker, F.; Grecchi, E.; Grecchi, F.; Francetti, L.; Del Fabbro, M. Treatment of medication-related osteonecrosis of the jaw (MRONJ). A systematic review. Eur. Rev. Med. Pharmacol. Sci. 2021, 25, 2662-2673.

9. Matsui, A.; Kurihara, J.; Morishima, H.; Suzuki, H.; Sato, S.; Yamauchi, K.; Takahashi, T. Medication related osteonecrosis of the jaw (MRONJ): A retrospective survey of a series of patients treated according to the AAOMS guidelines. J. Oral Maxillofac. Surg. Med. Pathol. 2015, 27, 757-763. [CrossRef]

10. Rosella, D.; Papi, P.; Giardino, R.; Cicalini, E.; Piccoli, L.; Pompa, G. Medication-related osteonecrosis of the jaw: Clinical and practical guidelines. J. Int. Soc. Prev. Community Dent. 2016, 6, 97-104. [PubMed]

11. Khan, A.A.; Morrison, A.; Hanley, D.A.; Felsenberg, D.; McCauley, L.K.; O’Ryan, F.; Reid, I.R.; Ruggiero, S.L.; Taguchi, A.; Tetradis, S.; et al. Diagnosis and Management of Osteonecrosis of the Jaw: A Systematic Review and International Consensus. J. Bone Miner. Res. 2015, 30, 3-23. [CrossRef] [PubMed]

12. Romeo, U.; Galanakis, A.; Marias, C.; Del Vecchio, A.; Tenore, G.; Palaia, G.; Vescovi, P.; Polimeni, A. Observation of Pain Control in Patients with Bisphosphonate-Induced Osteonecrosis Using Low Level Laser Therapy: Preliminary Results. Photomed. Laser Surg. 2011, 29, 447-452. [CrossRef] [PubMed]

13. Del Vecchio, A.; Tenore, G.; Luzi, M.C.; Palaia, G.; Mohsen, A.; Pergolini, D.; Romeo, U. Laser Photobiomodulation (PBM)—A Possible New Frontier for the Treatment of Oral Cancer: A Review of In Vitro and In Vivo Studies. Healthcare 2021, 9, 134. [CrossRef] [PubMed]

14. Mester, E.; Mester, A.F. The biomedical effects of laser application. Lasers Surg. Med. 1985, 5, 31-39. [CrossRef] [PubMed]

15. Karu, T.I.; Afanasyeva, N.I. Cytochrome c oxidase as the primary photoacceptor upon laser exposure of cultured cells to visible and near IR-range light. Dokl. Akad. Nauk. 1995, 342, 693-695.

16. Karu, T.I. Mitochondrial Signaling in Mammalian Cells Activated by Red and Near-IR Radiation. Photochem. Photobiol. 2008, 84, 1091-1099. [CrossRef] [PubMed]

17. Karu, T.I.; Pyatibrat, L.V.; Afanasyeva, S.I. Cellular Effects of Low Power Laser Therapy Can be Mediated by Nitric Oxyde. Lasers Surg. Med. 2005, 36, 307-314. [CrossRef]

18. Huang, Y.-Y.; Sharma, S.K.; Carroll, J.; Hamblin, M.R. Biphasic Dose Response in Low Level Light Therapy-An Update. Dose Response 2011, 9, 602-618. [CrossRef]

19. Calabrese, E.J.; Mattson, M.P. How does hormesis impact biology, toxicology, and medicine? Npj Aging Mech. Dis. 2017, 3, 13. [CrossRef]

20. Calabrese, E.J.; Baldwin, L.A. Hormesis: A Generalizable and Unifying Hypothesis. Crit. Rev. Toxicol. 2001, 31, 353-424. [CrossRef]

21. Rodrigo, S.M.; Cunha, A.; Pozza, D.H.; Blaya, D.S.; Moraes, J.F.; Weber, J.B.B.; De Oliveira, M.G. Analysis of the Systemic Effect of Red and Infrared Laser Therapy on Wound Repair. Photomed. Laser Surg. 2009, 27, 929-935. [CrossRef]

22. Del Vecchio, A.; Floravanti, M.; Boccassini, A.; Gaimari, G.; Vestri, A.; Di Paolo, C.; Romeo, U. Evaluation of the efficacy of a new low-level laser therapy home protocol in the treatment of temporomandibular joint disorder-related pain: A randomized, double-blind, placebo-controlled clinical trial. Cranio 2021, 39, 141-150. [CrossRef] [PubMed]

23. Romeo, U.; Del Vecchio, A.; Capocci, M.; Maggiore, C.; Ripari, M. The low level laser therapy in the management of neurological burning mouth syndrome. A pilot study. Ann. Stomatol. 2010, 1, 14-18.

24. Tenore, G.; Zimbalatti, A.; Rocchetti, F.; Graniero, F.; Gaglioti, D.; Mohsen, A.; Caputo, M.; Lollobrigida, M.; Lamazza, L.; De Biase, A.; et al. Management of Medication-Related Osteonecrosis of the Jaw (MRONJ) Using Leukocyte- and Platelet-Rich Fibrin (L-PRF) and Photobiomodulation: A Retrospective Study. J. Clin. Med. 2020, 9, 3505. [CrossRef] [PubMed] 
25. Mohsen, A.; Tenore, G.; Rocchetti, F.; Del Vecchio, A.; Ricci, R.; Barberi, W.; Cartoni, C.; Iori, A.P.; Pippi, R.; Polimeni, A.; et al. Photo-Biomodulation as a Prevention Modality of Oral Mucositis in Patients Undergoing Allogeneic Hematopoietic Stem Cell Transplantation. Appl. Sci. 2020, 10, 7479. [CrossRef]

26. Vescovi, P.; Meleti, M.; Merigo, E.; Manfredi, M.; Fornaini, C.; Guidotti, R.; Nammour, S. Case series of 589 tooth extractions in patients under bisphosphonates therapy. Proposal of a clinical protocol supported by Nd:YAG low-level laser therapy. Med. Oral Patol. Oral Cirugia Bucal 2013, 18, e680-e685. [CrossRef] [PubMed]

27. Lopes-Martins, R.A.; Marcos, R.L.; Leonardo, P.S.; Prianti, A.C.; Muscará, M.N.; Aimbire, F.; Frigo, L.; Iversen, V.V.; Bjordal, J.M. MASCC/ISOO clinical practice guidelines for the management of mucositis secondary to cancer therapy. Cancer 2020, 126, 4423-4431. [CrossRef]

28. Lopes-Martins, R.Á.B.; Marcos, R.L.; Leonardo, P.S.; Prianti, J.A.C.; Muscará, M.N.; Aimbire, F.; Frigo, L.; Iversen, V.V.; Bjordal, J.M. Effect of low-level laser (Ga-Al-As $655 \mathrm{~nm}$ ) on skeletal muscle fatigue induced by electrical stimulation in rats. J. Appl. Physiol. 2006, 101, 283-288. [CrossRef]

29. Hagiwara, S.; Iwasaka, H.; Okuda, K.; Noguchi, T. GaAlAs (830 nm) low-level laser enhances peripheral endogenous opioid analgesia in rats. Lasers Surg. Med. 2007, 39, 797-802. [CrossRef]

30. Chow, R.T.; David, M.A.; Armati, P.J. $830 \mathrm{~nm}$ laser irradiation induces varicosity formation, reduces mitochondrial membrane potential and blocks fast axonal flow in small and medium diameter rat dorsal root ganglion neurons: Implications for the analgesic effects of $830 \mathrm{~nm}$ laser. J. Peripher. Nerv. Syst. 2007, 12, 28-39. [CrossRef]

31. Desiderá, A.; Nascimento, G.; Gerlach, R.; Leite-Panissi, C.R.A. Laser therapy reduces gelatinolytic activity in the rat trigeminal ganglion during temporomandibular joint inflammation. Oral Dis. 2015, 21, 652-658. [CrossRef] [PubMed]

32. Jang, H.; Lee, H. Meta-Analysis of Pain Relief Effects by Laser Irradiation on Joint Areas. Photomed. Laser Surg. 2012, 30, 405-417. [CrossRef] [PubMed]

33. Tenore, G.; Mohsen, A.; Del Vecchio, A.; Palaia, G.; Migliau, G.; Capocci, M.; Gaimari, G.; Rocchetti, F.; Galanakis, A.; Romeo, U. Supportive pain management with super-pulsed low-level laser therapy of patients with medication related osteonecrosis of the jaw: Clinical trial. Senses Sci. 2017, 4, 386-394.

34. Lee, J.-Y.; Kim, I.-R.; Park, B.-S.; Kim, Y.-D.; Chung, I.-K.; Song, J.-M.; Shin, S.-H. Effect of low-level laser therapy on oral keratinocytes exposed to bisphosphonate. Lasers Med. Sci. 2015, 30, 635-643. [CrossRef] [PubMed]

35. Martins, M.A.T.; Martins, M.D.; Lascala, C.A.; Curi, M.M.; Migliorat, C.A.; Tenis, C.A.; Marques, M.M. Association of laser phototherapy with PRP improves healing of bisphosphonate-related osteonecrosis of the jaws in cancer patients: A preliminary study. Oral Oncol. 2012, 48, 79-84. [CrossRef] 